\title{
Insights into brain metastasis in patients with $A L K+$ lung cancer: is the brain truly a sanctuary?
}

\author{
Gouji Toyokawa $^{1} \cdot$ Takashi Seto $^{1} \cdot$ Mitsuhiro Takenoyama $^{1} \cdot$ Yukito Ichinose $^{1}$
}

Published online: 5 September 2015

(C) The Author(s) 2015. This article is published with open access at Springerlink.com

\begin{abstract}
Anaplastic lymphoma kinase (ALK) has been identified to exert a potent transforming activity through its rearrangement in non-small cell lung cancer (NSCLC), and patients (pts) with $A L K$ rearrangement can be treated more successfully with ALK inhibitors, such as crizotinib, alectinib, and ceritinib, than with chemotherapy. Despite the excellent efficacy of ALK inhibitors, resistance to these drugs is inevitably encountered in most $A L K$-rearranged pts. Cases of resistance are subtyped into three groups, i.e., systemic, oligo, and central nervous system (CNS) types, with the CNS being used to be considered a sanctuary. With regard to the management of CNS lesions in pts with ALK+ NSCLC, a growing body of evidence has gradually demonstrated the intracranial (IC) efficacy of ALK inhibitor (ALKi) in ALK+ NSCLC pts with brain metastases (BMs). Although the efficacy of crizotinib for the CNS lesions remains controversial, a recent retrospective investigation of $A L K+$ pts with BM enrolled in PROFILE 1005 and PROFILE 1007 demonstrated that crizotinib is associated with a high disease control rate for BM. However, $\mathrm{BM}$ comprises the most common site of progressive disease in pts with or without baseline BMs, which is a serious problem for crizotinib. Furthermore, alectinib can be used to achieve strong and long-lasting inhibitory effects on BM. In addition to alectinib, the IC efficacy of other next-generation ALK inhibitors, such as ceritinib, AP26113 and PF-06463922, has been demonstrated. In this article, we review the latest evidence regarding the BM and IC efficacy of ALK inhibitors in pts with $A L K+$ NSCLC.
\end{abstract}

Gouji Toyokawa

gouji104kawa@gmail.com

1 Department of Thoracic Oncology, National Kyushu Cancer Center, 3-1-1 Notame, Minami-ku, Fukuoka 811-1395, Japan
Keywords Non-small cell lung cancer · Anaplastic lymphoma kinase $($ ALK) $\cdot$ Brain metastasis $\cdot$ ALK inhibitors

\section{Introduction}

Rearrangement in the anaplastic lymphoma kinase (ALK) gene is one of the potent oncogenic drivers in patients (pts) with non-small cell lung cancer (NSCLC) and occurs in approximately $5 \%$ of cases $[1,2]$. Tyrosine kinase inhibitors (TKIs) against ALK, such as crizotinib, alectinib, and ceritinib, have recently been developed and shown to exert a potent antitumor activity in pts with $A L K$-rearranged NSCLC [3-9]. With regard to crizotinib, which has been originally developed as a c-Met inhibitor, the response rate (RR) and progression-free survival (PFS) of crizotinib in first- and second-line settings for advanced $A L K+$ NSCLC are 74 and $65 \%$ and 10.9 and 7.7 months, respectively, which are significantly better than those achieved with standard chemotherapy $[5,6]$. Alectinib, a next-generation ALK inhibitor (ALKi), is also known to exhibit a high antitumor activity for pts with $A L K+$ NSCLC, i.e., RR and PFS of $93.5 \%$ and 27.7 months, respectively [7]. Critically, alectinib is effective for $A L K^{+}$ NSCLC pts with a history of prior crizotinib treatment [8] and ceritinib has been shown to demonstrate high efficacy for pts with $A L K+$ NSCLC treated with or without prior therapy with crizotinib [9].

Metastasis to the central nervous system (CNS) is a difficult concern to be resolved in many types of cancer as a result of inadequate penetration of antitumor agents, difficult accessibility, and neurological symptoms leading to a decreased performance status, and lung cancer is the leading cancer to metastasize to the brain. According to the SEER database, lung cancer occurred in $19.9 \%$ of $16,210 \mathrm{pts}$, followed by melanoma at $6.9 \%[10,11]$. In pts with advanced NSCLC, 
approximately $10-20 \%$ of cases are considered to be accompanied by CNS metastases prior to first-line treatment [12, 13]. With regard to the incidence of brain metastasis (BM) in pts with $A L K+$ NSCLC who are naïve to ALKi, several retrospective studies have reported rates ranging from approximately 20 to $30 \%$, which is comparable to that observed in epidermal growth factor receptor (EGFR)-mutated NSCLC pts $[14,15]$. In large trials examining ALKi, the frequency of BM in ALKi-naïve pts has been reported to range from approximately 25 to $40 \%$, which is high in pts with a history of chemotherapy [5-7, 16]. Furthermore, $A L K$-rearranged NSCLC pts exhibiting a history of prior ALKi treatment are reported to harbor a high incidence of CNS metastases, i.e., from approximately 45 to $70 \%$, which suggests that BM is the most common pattern of failure of ALKi [8, 9, 17-21]. Therefore, it is crucial to properly treat CNS lesions as well as systemic lesions.

With regard to the efficacy of ALKi for BM in $A L K^{+}$ NSCLC pts, the efficacy of crizotinib was analyzed in retrospective analyses of the PROFILE 1005 and PROFILE 1007 trials [22]. The disease control rate (DCR) and RR in previously untreated and treated BM cases were 56 and $62 \%$, and 18 and $33 \%$, respectively. In addition, several reports have indicated that alectinib exhibits excellent antitumor efficacy for CNS metastases in $A L K+$ NSCLC pts with or without prior ALKi treatment, including crizotinib and ceritinib [7, 8, 19, 20, 23-25]. According to the results of AF-002JG, the intracranial (IC) objective RR was intriguingly $52 \%$, with a complete response rate of $29 \%$ [8]. In concordance with the clinical efficacy observed in $A L K+$ pts, the remarkable efficacy of alectinib has been demonstrated in experimental models of IC metastases [26, 27]. The high efficacy of alectinib for $A L K^{+}$ CNS metastases is considered to be due to its high penetration to the brain as well as poor efflux from the brain, owing to experimental results demonstrating that alectinib might not be transported by $P$-glycoprotein $(P$-gp) efflux protein, a key protein for blood-brain barrier (BBB) penetration [26]. In addition to alectinib, ceritinib has been shown to be effective for BM, and novel compounds, such as AP26113 and PF06463922, have also been demonstrated to be effective for CNS lesions [16-18, 21, 28].

Therefore, a growing body of evidence has been accumulated for BM in pts with $A L K+$ NSCLC. In this review article, we review up-to-date evidence on recent clinical and basic results regarding $\mathrm{BM}$ and discuss the optimal management of $\mathrm{BM}$ in pts with $A L K$-positive NSCLC.

\section{Incidence of IC metastases in pts with $A L K+$ NSCLC}

The brain is a devastating metastatic site of malignancies, including lung cancer, as metastasis to the brain might result in neurological dysfunction and cognitive impairment, which can lead to an impaired quality of life. The presence of IC metastases is known to be associated with a poor prognosis. According to the report by Paul and colleagues, the median survival time of pts with BM is 7.0 months from the start of treatment of BM and, in particular, pts at high risk, as defined based on various determinants, including the number of BM lesions, achieve a survival as short as 3.0 months [29].

ALK is normally expressed in the CNS, small intestine, and testes and is considered to play a role in the development of the nervous system; however, its involvement in IC metastasis and its significance in normal organs have yet to be elucidated [30]. With regard to the baseline frequency of $\mathrm{BM}$ in pts with $A L K+\mathrm{NSCLC}$ at the time of diagnosis of the disease, two retrospective studies showed a frequency of approximately $25 \%$, which is comparable to that observed in other subsets of NSCLC driven by EGFR and Kirsten rat sarcoma viral oncogene homolog $(K R A S)[14,15]$. This incidence is consistent with that reported in the PROFILE 1014 trial, which compared crizotinib with chemotherapy in pts with $A L K$-rearranged NSCLC as a first-line therapy; i.e., the frequency of BM in both arms was 26 and $27 \%$, respectively [6].

With regard to the incidence of CNS metastases in ALKinaïve $A L K+$ NSCLC pts previously treated with chemotherapy, the PROFILE 1007 trial, which compared crizotinib with pemetrexed or docetaxel as a second-line treatment in ALKinaïve NSCLC pts, showed that the prevalence of BM was approximately $35 \%$ in both arms, which is higher than that observed in the first-line PROFILE 1014 study (Table 1) [5]. Similar to this incidence, a retrospective exploratory analysis of the PROFILE 1015 and PROFILE 1007 trials showed that $275(31 \%)$ of the enrolled $888 A L K+$ pts had BM without any symptoms [22]. A phase II study (AF-001JP) that investigated the efficacy of alectinib at a dose of $300 \mathrm{mg}$ twice daily for ALKi-naïve NSCLC pts who had received one or more lines of chemotherapy showed almost the same prevalence (33\%) of BM as that seen in the retrospective study of PROFILE 1005 and PROFILE 1007 [7]. In the ASCEND-3 study of ceritinib in ALKi-naïve pts who had received one to three prior antineoplastic regimens, the prevalence of CNS metastasis was $40.3 \%(50 / 124)$ [16].

With regard to the incidence of BM in pts with $A L K$ rearrangement previously treated with ALKi, several prospective studies have reported the detailed prevalence of BM in such populations, which ranges from approximately 40 to $70 \%$, as shown in Table 1 [8, 16-21, 28]. Almost all pts enrolled in these studies had been treated with crizotinib, suggesting that $\mathrm{BM}$ is very common in pts with crizotinib-treated $A L K+$ NSCLC. In fact, a retrospective study by Weickhardt et al. showed that 13 (46\%) among 28 cases of disease progression on crizotinib were identified to be due to BM [31]. Furthermore, a retrospective investigation of the PROFILE 1005 and 
Table 1 Frequency of BM in the trials regarding ALK inhibitors and efficacy of ALK inhibitors for BM in pts with ALK+ NSCLC

\begin{tabular}{|c|c|c|c|c|c|c|c|c|}
\hline \multirow[t]{2}{*}{ Trial } & \multirow{2}{*}{$\begin{array}{l}\text { Treatment } \\
\text { regimen }\end{array}$} & \multirow{2}{*}{$\begin{array}{l}\text { No. } \\
\text { of pts }\end{array}$} & \multirow{2}{*}{$\begin{array}{l}\text { Frequency } \\
\text { of BM, } \\
n(\%)\end{array}$} & \multirow{2}{*}{$\begin{array}{l}\text { Line } \\
\text { of Tx }\end{array}$} & \multirow[t]{2}{*}{ Prior ALKi } & \multirow[t]{2}{*}{ Target lesion } & \multicolumn{2}{|c|}{ Intracranial response (target lesion) } \\
\hline & & & & & & & DCR & $\mathrm{RR}$ \\
\hline PROFILE 1007 [5] & $\begin{array}{l}\text { Crizotinib } \\
\text { PEM or DOC }\end{array}$ & $\begin{array}{l}173 \\
174\end{array}$ & $\begin{array}{l}60(35) \\
60(34)\end{array}$ & 2 nd & No & Not described & Not described & \\
\hline \multirow[t]{2}{*}{ PROFILE 1014 [6] } & Crizotinib & 172 & $45(26)$ & $1 \mathrm{st}$ & No & Not described & $56 \%$ at 24 weeks & Not described \\
\hline & $\begin{array}{l}\text { PEM }+ \text { CBDCA } \\
\text { or CDDP }\end{array}$ & 171 & $47(27)$ & & & & $25 \%$ at 24 weeks & Not described \\
\hline $\begin{array}{l}\text { PROFILE } 1005 \\
\text { and PROFILE } \\
1007 \text { [22] }\end{array}$ & Crizotinib & 888 & $275(31)$ & $\geq 2$ nd & No & $\begin{array}{l}22 \text { (previously } \\
\text { untreated) }\end{array}$ & $\begin{array}{l}56 \% \text { at } 12 \text { weeks } \\
\text { (previously } \\
\text { untreated) }\end{array}$ & $\begin{array}{l}18 \% \text { (previously } \\
\text { untreated) }\end{array}$ \\
\hline AF-001JP [7] & Alectinib & 46 & $15(33)$ & $\geq 2$ nd & No & Not described & Not described & \\
\hline AF-002JG [8] & Alectinib & 47 & $21(45)$ & $\geq 2$ nd & Yes (crizotinib) & 9 & $77.8 \%$ & $55.6 \%$ \\
\hline NP28673 [19] & Alectinib & 138 & $84(61)$ & $\geq 2$ nd & Yes (crizotinib) & 35 & $85.7 \%$ & $57.1 \%$ \\
\hline NP28761 [20] & Alectinib & 87 & $52(60)$ & $\geq 2$ nd & Yes (crizotinib) & 16 & $100 \%$ & $68.8 \%$ \\
\hline JP28927 [53] & Alectinib & 35 & $23(65.7)$ & $\geq 1 \mathrm{st}$ & $\begin{array}{l}\text { Yes (29/35, crizotinib } \\
\text { and other ALK } \\
\text { inhibitors) }\end{array}$ & 2 & $100 \%$ & $100 \%$ \\
\hline ASCEND-1 [17] & Ceritinib & 246 & $124(50.4)$ & $\geq 1 \mathrm{st}$ & $\begin{array}{l}\text { Yes }(98 / 124, \text { other } \\
\text { ALK inhibitors) }\end{array}$ & 29 & $58.6 \%$ & $34.5 \%$ \\
\hline ASCEND-2 [18] & Ceritinib & 140 & $100(71.4)$ & $\geq 2$ nd & Yes (crizotinib) & 33 & $84.8 \%$ & $39.4 \%$ \\
\hline ASCEND-3 [16] & Ceritinib & 124 & $50(40.3)$ & $\geq 2$ nd & No & 17 & $82.4 \%$ & $58.8 \%$ \\
\hline AP26113 [21] & AP26113 & 79 & $52(66)$ & $\geq 1 \mathrm{st}$ & Yes (71/79, crizotinib) & 15 & $87 \%$ & $53 \%$ \\
\hline PF-06463922 [28] & PF-06463922 & $44^{\mathrm{a}}$ & $52(66)$ & $\geq 1$ st & Yes $(37 / 44$, ALKi) & 14 & $72 \%$ & $36 \%$ \\
\hline
\end{tabular}

$B M$ brain metastasis, No. number, $p t s$ patients, $T x$ therapy, $D C R$ disease control rate, $R R$ response rate, $I C$ intracranial, $D O R$ duration of response, $P E M$ pemetrexed, $D O C$ docetaxel, $C B D C A$ carboplatin, $C D D P$ cisplatin

${ }^{a}$ Thirty-three (75\%) and $11(25 \%)$ were $A L K+$ and $R O S 1+$ patients

PROFILE 1007 trials demonstrated that the CNS was the most frequently affected organ in cases of progressive disease (PD) in pts on crizotinib with or without a previous history of treatment for baseline BM, which ranged from 70 to $72 \%$ [22]. In addition, with regard to the cumulative risk of IC metastasis in $A L K+$ NSCLC pts, Rangachari and colleagues reported that the incidence of BM in $A L K$-rearranged pts at 1,2, and 3 years from the initial diagnosis was $23.8,45.5$, and $58.4 \%$, respectively [15]. Therefore, IC metastases are more commonly observed after the failure of antineoplastic agents including ALKi, which is one of the most confusing issues to be addressed in the management of pts with $A L K$-rearranged NSCLC.

\section{Antitumor activity of ALKi against BM in pts with $A L K+$ NSCLC}

CNS metastasis is usually insensitive to chemotherapy, and the RR of chemotherapy for BM from solid tumors has been reported to be approximately 20 to $40 \%$, suggesting that the brain is a sanctuary site in the treatment of pts with advanced lung cancer [32]. With regard to the efficacy of targeted therapy for BM arising from lung cancer, several studies have reported that erlotinib, a representative targeted agent, might be effective for CNS lesions. Erlotinib has been found to achieve a longer survival time in $E G F R$-mutated pts with $\mathrm{BM}$ compared with gefitinib, and the higher efficacy of erlotinib versus gefitinib is assumed to be due to the higher concentration and penetration of erlotinib in the cerebrospinal fluid (CSF) [33, 34]. In addition, the proportion of CNS PD is higher in cases of gefitinib compared with erlotinib: gefitinib versus erlotinib, approximately $35 \%$ versus up to $10 \%$ [35-38]. Hence, the efficacy of molecular-targeted agents for $\mathrm{BM}$ has gradually been clarified.

With regard to the efficacy of ALKi for CNS metastasis in pts with $A L K$ rearrangement-positive NSCLC, much evidence was reported at the ASCO Annual Meeting in 2015 (Table 1), and in this section, we review this evidence in detail. In order to clarify the antitumor effect of each ALKi agent, the DCR and RR for the target lesions are specified in Table 1.

\subsection{Crizotinib}

The PROFILE trials demonstrated that crizotinib, a first-inclass ALK TKI, achieves a significantly higher response in the systemic lesions of $A L K+$ NSCLC pts as compared with chemotherapy; however, it was not fully clarified whether 
crizotinib is effective for CNS metastasis [3-6]. In the PROFILE 1014 trial, the IC DCR at 24 weeks after the start of treatment was reported and crizotinib and first-line standard chemotherapy of platinum agents with pemetrexed achieved rates of 56 and $25 \%$, respectively, with a statistically significant difference (Table 1). A large retrospective study of the PROFILE 1015 and PROFILE 1007 trials examined the efficacy of crizotinib for BM in pts with $A L K$ rearrangement with or without a history of prior cranial radiotherapy [22]. Among 888 pts enrolled in these trials, 275 pts ( $31 \%$ ) were judged to harbor asymptomatic BM and divided into cases previously untreated or treated with radiotherapy ( $n=109$ and 166, respectively). The DCRs at 12 weeks in the previously untreated or treated BM cases were $56 \%$ (95\% confidence interval (CI) 46-66) and $62 \%$ (95\% CI 54-70), respectively, and the RRs of crizotinib in the target lesion in BM cases previously untreated or treated with radiation were $18 \%$ (95\% CI 5-40) and $33 \%$ (95\% CI 13-59), respectively. Although the difference in the RR observed between the two groups appears to be significant, attention should be paid to interpreting this result because radiotherapy for BM prior to enrollment in these studies might have affected the RR. The IC durations of response (DORs) in previously treated or untreated pts with a confirmed objective response was 26.4 (95\% CI 6.1-59.3) and not reached (95 \% CI 6.0-59.9), respectively. Furthermore, the studies showed that systemic PFS was not affected by the presence or absence of BM at baseline. Intriguingly, non-target or new lesions in the brain accounted for $71 \%$ of RECIST PD cases in pts with baseline BM and $25 \%$ of PD cases in pts without baseline BM, suggesting that the CNS remained the dominant site of acquired resistance to crizotinib in the pts with or without BM at baseline.

Furthermore, several case reports have reported the contradictory efficacy of crizotinib for CNS lesions, including intramedullary spinal cord metastasis and leptomeningeal carcinomatosis, in $A L K+$ NSCLC pts [39-45]. The rapid and long-lasting response of BM to crizotinib was recently reported by two groups [39, 40], and high-dose crizotinib has been shown to temporarily control BM refractory to standard-dose crizotinib [42]. In contrast, some reports have suggested that $\mathrm{BM}$ is insensitive to crizotinib, which leads to the notion that the brain is a sanctuary site or Achilles heel $[43,44]$. Importantly, a report by Costa and colleagues examined the concentration of crizotinib in the CSF of an ALK+ NSCLC pt who had progressed on crizotinib for BM and was treated with whole brain irradiation (WBI) and then resumed crizotinib after WBI [43]. That report demonstrated that concentration of crizotinib restarted after WBI in the CSF was as low as $0.616 \mathrm{ng} / \mathrm{ml}$, while the plasma concentration of the agent was $237 \mathrm{ng} / \mathrm{ml}$, with a CSF-to-plasma ratio of 0.0026 . This result suggests that the possible poor BBB penetration of crizotinib might explain the failure of crizotinib to be effective for BM in cases of $A L K+$ NSCLC. Another report published by Metro et al. also analyzed the CSF concentrations of crizotinib in two pts with $A L K$ rearrangement whose CNS lesions were successfully treated with crizotinib [46]. In one case, in which the pt was naive to radiotherapy for CNS lesions and experienced a complete CNS response, the concentrations of crizotinib in the serum and CSF were 587 and $0.35 \mathrm{ng} / \mathrm{ml}$, respectively, with a CSF-to-serum ratio of 0.0006 . In another case, in which the pt progressed on crizotinib for BM and was treated with WBI and subsequently continued crizotinib with a temporary discontinuation during $\mathrm{WBI}$, the concentrations of crizotinib in the serum and CSF were 800 and $0.80 \mathrm{ng} / \mathrm{ml}$, respectively, with a CSF-to-serum ratio of 0.001. Intriguingly, despite the poor CNS concentration of crizotinib, the CNS lesions in these two pts were successfully tread with crizotin$\mathrm{ib}$, suggesting the possible involvement of other factors in the CNS accounting for the benefit of crizotinib. Based on these findings, a low CSF-to-serum ratio alone does not explain the insensitivity of crizotinib to BM, which should be clarified in further investigations.

\subsection{Alectinib}

Alectinib/CH5424802 was developed to be highly selective against ALK and later identified to block ret proto-oncogene $[47,48]$. Preclinical experiments have demonstrated that this agent is capable of blocking mutated forms of ALK, including a gatekeeper mutation of L1196M conferring crizotinib resistance, as well as wild-type ALK $[47,49]$. With regard to the antitumor efficacy of alectinib for BM, intracranial tumor implantation mouse models of $A L K+$ NSCLC cells have demonstrated that alectinib potently induces IC tumor regression compared with crizotinib, resulting in prolonged survival $[26,27]$. This potent antineoplastic activity of alectinib against $\mathrm{BM}$ is assumed to be due to high rate of penetration of the agent into the brain, and intriguingly, it has been suggested that alectinib might not be transported by $P$-gp, which is expressed in the $\mathrm{BBB}$ and plays a key role in $\mathrm{BBB}$ penetration (Fig. 1) [26, 50]. In addition, data for five alectinib-treated pts with available plasma and CSF samples showed a relationship

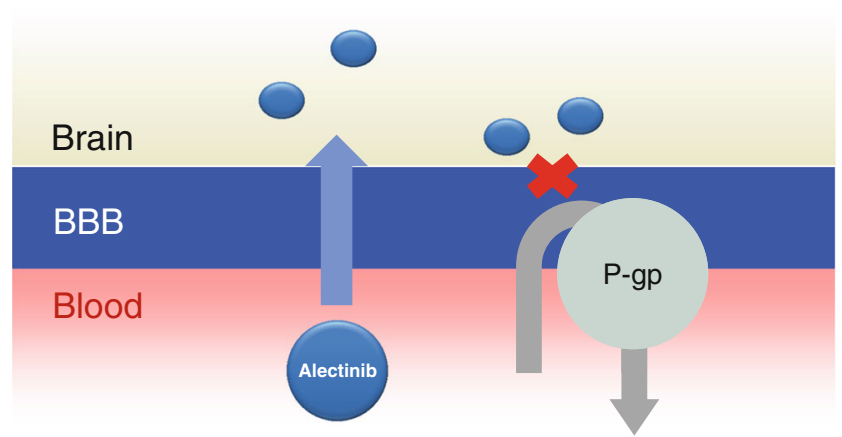

Fig. 1 Alectinib is not a substrate of P-gp, which is expressed in the BBB and plays a key role in BBB penetration. $B B B$ blood-brain barrier, $P$-gp $P$ glycoprotein 
between the concentration of alectinib in the CSF and paired systemic unbound alectinib [8].

The phase II portion of the AF-001JP trial included $33 \%$ pts with BM among 46 pts enrolled at baseline, although the detailed responses have not yet been reported [7, 51]. Four (33\%) of 12 pts who experienced PD showed CNS progression, and half of the pts with baseline IC metastasis continued to be treated with alectinib without any PD at brain or systemic sites. The median PFS, which was not reached and was estimated to reach beyond 29 months, was affected by the presence of BM at baseline, i.e., 35.3 months versus not reached in the pts with or without BM at baseline, respectively. Furthermore, other studies investigating alectinib, such as AF-002JG, NP2867, and NP28761, were recently designed to evaluate crizotinib-resistant or intolerant pts with $A L K$ translocation and showed detailed data regarding the efficacy of alectinib for IC lesions $[8,19,20]$. In the AF-002JG study, among 21 pts with BM at baseline, six (29\%), five (24\%), eight (38\%), and two (10\%) achieved a complete response (CR), partial response, stable disease, and PD, respectively [8]. When limited to nine pts with measurable BM lesions, the objective RR (ORR) and DCR were as high as 55.6 and $77.8 \%$, respectively. Intriguingly, one of two pts experiencing IC PD, despite a systemic good response, had been treated with stereotactic radiotherapy for BM, and only one lesion was enlarged, with other lesions being decreased. Thereafter, surgical resection was performed for the enlarging lesion, which was confirmed to be necrotic, without any viable cancer cells, suggesting pseudo-progression (PsP). In addition to this report, $\mathrm{Ou}$ et al. reported two pts who experienced radiation necrosis presenting as PsP when treated with alectinib for previously irradiated BM [52]. These results underline the importance of distinguishing truly progressive disease from PsP when treating previously radiated IC lesions with alectinib, although the optimal way to do this has yet to be established, other than surgical resection.

The phase II NP28673 and NP28761 studies are aimed to examine the efficacy and safety of alectinib at a dose of $600 \mathrm{mg}$ twice daily for pts with $A L K+$ NSCLC who progressed on or did not respond to crizotinib $[19,20]$. In the NP28783 trial, the frequency of BM was 84 (61\%) among 138 pts and 35 pts had measurable CNS lesions. The IC ORR and DCR in pts with measurable BM were $57.1 \%(95 \% \mathrm{CI}$ 39.4-73.7) and 85.7\% (95\% CI 69.7-95.2), respectively, and the CR was observed in seven pts (20.0\%). In addition, the DOR in the CNS was as long as 10.3 months (95\% CI 7.611.2). Moreover, the RR in the pts treated with or without prior radiation was 39.3 and $52.2 \%$, respectively, and considering the possibility of PsP, attention should be paid to interpreting the slightly low RR values noted in pts previously treated with radiation. The NP28761 trial also demonstrated the excellent efficacy of alectinib for IC lesions: the RR and DCR in the pts with measurable BM at baseline were 68.8 and
$100 \%$, respectively. The antitumor activity of alectinib for BM in cases of $A L K+$ NSCLC pre-treated with crizotinib was also reported in the JP28927 study [53]. With regard to the relapse pattern, nine out of $23(65.7 \%)$ pts with baseline $\mathrm{BM}$ were identified to progress on alectinib and all pts, except one, progressed at sites other than the brain. Furthermore, alectinib has been reported to be effective for CNS metastasis associated with leptomeningeal involvement previously treated with crizotinib and alectinib [25]. Therefore, alectinib is highly effective for CNS lesions in ALK+ NSCLC pts. Difference in systemic and IC efficacy between 300 and $600 \mathrm{mg}$ twice daily, if any, should be investigated in future studies.

\subsection{Ceritinib}

Ceritinib (LDK378), a highly selective, orally available ALK inhibitor, has been shown to inhibit ALK with 20-fold potency to that of crizotinib and is effective for ALK with several mutations that confer resistance to crizotinib in preclinical experiments [54]. In humans, a phase I study investigating ceritinib demonstrated ORR in pts with or without prior crizotinib treatment of 56 and of $58 \%$, respectively [9], and crizotinib followed by ceritinib has been shown to prolong combined PFS [55]. With regard to the efficacy of ceritinib for IC metastasis, a preclinical rat model showed that ceritinib penetrates the BBB with a brain-to-blood exposure ratio of approximately $15 \%$ [56], and the IC efficacy of ceritinib has been observed in pts previously treated with or without crizotinib [9].

More detailed data on the efficacy of ceritinib for CNS metastasis were reported in the ASCEND studies. The ASCEND-1 study included 124 (50.4\%) pts with baseline BM among 246 enrolled pts, and 98 of the pts with BM had been treated with other ALK inhibitors agents. The IC RR and DCR in the pts with measurable BM were $34.5 \%(95 \% \mathrm{CI}$ 17.9-54.3) and 58.6\% (95\% CI 38.9-76.5), respectively [17]. Prior ALKi treatment affected the RR and IC DCR: the RR and IC DCR values in the pts with or without prior ALKi treatment were 29.2 and $60.0 \%$, and 58.3 and $60.0 \%$, respectively. The IC median PFS was reported to be 8.3 and 7.0 months and not estimable in all pts, the pts with prior ALKi and the ALKi-naïve pts. The ASCEND-2 trial is a phase II study of ceritinib in pts with $A L K+$ NSCLC previously treated with chemotherapy and crizotinib, and all pts had a history of crizotinib treatment as the last prior systemic anticancer therapy [18]. One hundred pts $(71.4 \%)$ had a history of prior radiotherapy for BM, and the IC RR and DCR in 33 pts with target lesions in the brain were $39.4 \%$ (95\% CI 22.9-57.9) and $84.8 \%$ (95 \% CI 68.1-94.9), respectively. In addition, the ASCEND-3 study aimed to investigate the antitumor efficacy and safety of ceritinib in ALKi-naïve pts with ALK rearrangement who had progressed on one to three lines of chemotherapy [16]. Among 50 (40.3\%) pts with BM at baseline, 27 pts 
$(54.0 \%)$ had been treated with prior radiotherapy to the brain. The IC RR and DCR in 17 pts with target lesions in the brain were $58.9 \%$ (95 \% CI 32.9-81.6) and $82.4 \%$ (95\% CI 56.696.2), respectively. These findings demonstrate that ceritinib is highly effective for pts with BM, and intriguingly, the antineoplastic effect of ceritinib against BM is high for pts without a history of ALKi treatment compared with those pre-treated with other ALK inhibitors.

\subsection{Other ALK inhibitors}

Other ALK inhibitors, such as AP26133 and PF-06463922, have been also shown to be effective for IC metastasis [21, 28]. The phase I/II study of AP26113 included 137 pts with advanced malignancies, including 79 pts with $A L K$ rearranged NSCLC, of whom $52(66 \%)$ of $79 A L K+$ NSCLC pts had BM at baseline [21]. The IC ORR and DCR in the $A L K+$ pts with measurable BM were as high as 53 and $87 \%$, respectively. With regard to PF-06463922, the IC RR and DCR were 36 and $72 \%$, respectively [28], and the high IC efficacy of the agent was confirmed in preclinical IC models [57]. Furthermore, IC data for other novel ALK inhibitors, such as X-396, TSR-11, and so on, are anticipated to be reported in the near future $[58,59]$.

\section{Beyond PD use of ALKi for BM}

In clinical settings using molecular-targeted agents, physicians usually experience cases of PD only in the CNS [60]. Several retrospective studies have demonstrated that the use of crizotinib beyond progressive disease (CBPD) combined with cranial radiotherapy for CNS PD might offer a survival benefit $[31,61,62]$. Takeda and colleagues retrospectively investigated seven pts with $A L K$ rearrangement who progressed on crizotinib in isolated CNS lesions and resumed crizotinib after local ablative therapy (LAT), including stereotactic radiotherapy (SRT) for three pts and WBI for four pts [60]. The median PFS from the first initiation of crizotinib was 5.5 months, and all pts were able to continue the treatment with crizotinib for at least 4 months after LAT without disease progression, suggesting that the addition of LAT to crizotinib for isolated BM might prolong the total PFS. In addition to this study, Weickhardt et al. examined LAT for oligo-progressive disease, including brain and extra-CNS lesions, in 25 pts with $E G F R$-mutated or $A L K$-rearranged NSCLC who progressed on erlotinib or crizotinib and were judged to be suitable for LAT [31]. The PFS achieved with erlotinib and crizotinib was 13.8 and 9.0 months, respectively, and LAT for CNS, which was a site of first progression, prolonged the PFS for more than 7.0 months. Although grade $3 / 4$ fatigue was reported in two pts who received WBI, no other grade 3/4 radiation-related toxicities were observed.
Furthermore, a retrospective investigation of $A L K+$ pts enrolled in the PROFILE 1001 or PROFILE 1005 trials who were able to continue CBPD demonstrated that CBPD might be associated with prolonged survival: the OS from the time of PD in the pts with or without CBPD was 16.4 versus 2.9 months, respectively (hazard ratio (HR) $0.27,95 \% \mathrm{CI}$ $0.17-0.42 ; P<0.0001)$ [61]. In addition, the OS from the first dose of crizotinib in the pts with or without CBPD was 29.6 and 10.8 months, respectively (HR $0.30,95 \%$ CI $0.19-0.46$; $P<0.0001)$. It should be noted that $51 \%$ of the pts with CBPD had the brain as a site of PD, while the pts without CBPD had both the liver (37\%) and the brain (28\%) as PD sites, suggesting that pts with progressive disease in the CNS might benefit significantly from CBPD.

Therefore, CBPD for CNS PD appears to prolong survival. Hence, should physicians always consider CBPD in pts who relapse on crizotinib in isolated CNS lesions? If we have a choice to use next-generation ALKi, such as alectinib, after failure of or intolerance to crizotinib, the answer seems to be no. As described above, next-generation ALK inhibitors, specifically alectinib, are highly effective for CNS lesions pretreated with crizotinib. In addition to this point, considering the possible long survival achieved with two or more ALK inhibitors and cytotoxic chemotherapy and the potential for late complications of radiotherapy, such as radiation necrosis and encephalopathy, even isolated CNS metastases should be considered truly progressive and crizotinib should be changed to another ALKi. However, if all available ALK inhibitors are completed, ALKi beyond PD combined with LAT for BM should be considered, because cytotoxic chemotherapy is usually ineffective for such lesions. Since these strategies are not based on definitive data, future studies are warranted to investigate which strategy, using ALKi beyond PD concurrently with LAT for BM or switching to other ALK inhibitors or cytotoxic chemotherapy, is better in terms of the survival benefit and safety.

\section{Conclusion}

We herein described the detailed data on the frequency of BM and efficacy of various ALK inhibitors for BM. Although the brain is thought to be one of the most invulnerable sites, recent trials have demonstrated that novel ALK inhibitors exhibit high antineoplastic effects on CNS lesions. Future studies are warranted to elucidate the most optimal management of $\mathrm{BM}$ in pts with $A L K$-rearranged NSCLC.

Acknowledgments We thank Brian Quinn for providing critical comments on the manuscript.

Conflict of interest Dr. Ichinose, Dr. Seto, Dr. Takenoyama, and Dr. Toyokawa have potential conflicts of interest to disclose with Pfizer Japan, Inc., Novartis Pharma K.K., and Chugai Pharmaceutical Co., Ltd. 
Funding information This work was supported by Grant-in-Aid for Young Scientists (B) (JSPS KAKENHI Grant Number 30627261) and the Uehara Memorial Foundation (Japan).

Open Access This article is distributed under the terms of the Creative Commons Attribution 4.0 International License (http:// creativecommons.org/licenses/by/4.0/), which permits unrestricted use, distribution, and reproduction in any medium, provided you give appropriate credit to the original author(s) and the source, provide a link to the Creative Commons license, and indicate if changes were made.

\section{References}

1. Soda, M., Choi, Y. L., Enomoto, M., Takada, S., Yamashita, Y., Ishikawa, S., et al. (2007). Identification of the transforming EML4-ALK fusion gene in non-small-cell lung cancer. Nature, 448(7153), 561-566.

2. Gainor, J. F., Varghese, A. M., Ou, S. H., Kabraji, S., Awad, M. M., Katayama, R., et al. (2013). ALK rearrangements are mutually exclusive with mutations in EGFR or KRAS: an analysis of 1,683 patients with non-small cell lung cancer. Clinical Cancer Research, 19(15), 4273-4281.

3. Kwak, E. L., Bang, Y. J., Camidge, D. R., Shaw, A. T., Solomon, B., Maki, R. G., et al. (2010). Anaplastic lymphoma kinase inhibition in non-small-cell lung cancer. The New England Journal of Medicine, 363(18), 1693-1703.

4. Camidge, D. R., Bang, Y. J., Kwak, E. L., Iafrate, A. J., VarellaGarcia, M., Fox, S. B., et al. (2012). Activity and safety of crizotinib in patients with ALK-positive non-small-cell lung cancer: updated results from a phase 1 study. The Lancet Oncology, 13(10), 10111019.

5. Shaw, A. T., Kim, D. W., Nakagawa, K., Seto, T., Crinó, L., Ahn, M. J., et al. (2013). Crizotinib versus chemotherapy in advanced ALK-positive lung cancer. The New England Journal of Medicine, 368(25), 2385-2394.

6. Solomon, B. J., Mok, T., Kim, D. W., Wu, Y. L., Nakagawa, K., Mekhali, T., et al. (2014). First-line crizotinib versus chemotherapy in ALK-positive lung cancer. The New England Journal of Medicine, 371(23), 2167-2177.

7. Seto, T., Kiura, K., Nishio, M., Nakagawa, K., Maemondo, M., Inoue, A., et al. (2013). CH5424802 (RO5424802) for patients with ALK-rearranged advanced non-small-cell lung cancer (AF-001JP study): a single-arm, open-label, phase 1-2 study. The Lancet Oncology, 14(7), 590-598.

8. Gadgeel, S. M., Gandhi, L., Riely, G. J., Chiappori, A. A., West, H. L., Azada, H. L., et al. (2014). Safety and activity of alectinib against systemic disease and brain metastases in patients with crizotinib-resistant ALK-rearranged non-small-cell lung cancer (AF-002JG): results from the dose-finding proportion of a phase 1/2 study. The Lancet Oncology, 15(10), 1119-1128.

9. Shaw, A. T., Kim, D. W., Mehra, R., Tan, D. S., Felip, E., Chow, L. Q., et al. (2014). Ceritinib for ALK-rearranged non-small-cell lung cancer. The New England Journal of Medicine, 370(13), 11891197.

10. Barnholtz-Sloan, J. S., Sloan, A. E., Davis, F. G., Vigneau, F. D., Lai, P., \& Sawaya, R. E. (2004). Incidence proportions of brain metastases in patients diagnosed (1973 to 2001) in the Metropolitan Detroit Cancer Surveillance System. Journal of Clinical Oncology, 22(14), 2865-2872.

11. Schouten, L. J., Rutten, J., Huveneers, H. A., \& Twijnstra, A. (2002). Incidence of brain metastases in a cohort of carcinoma of the breast, colon, kidney, and lung and melanoma. Cancer, 94(10), 2698-2705.
12. Arrieta, O., Saavedera-Perez, D., Kuri, R., Aviles-Salas, A., Martinez, L., Mendoza-Posada, D., et al. (2009). Brain metastasis development and poor survival associated with carcinoembryonic antigen (CEA) level in advanced non-small cell lung cancer: a prospective analysis. BMC Cancer. doi:10.1186/1471-2407-9-119.

13. Hanna, N. H., Dahlberg, S. E., Kolesar, J. M., Aggarwal, C., Hirsch, F. R., Ramalingam, S. S., et al. (2015). Three-arm, randomized, phase 2 study of carboplatin and paclitaxel in combination with cetuximab, cixutumumab, or both for advanced nonsmall cell lung cancer (NSCLC) patients who will not receive bevacizumab-based therapy: an Eastern Cooperative Oncology Group (ECOG) study (E4508). Cancer. doi:10.1002/cncr.29308.

14. Doebele, R. C., Lu, X., Sumey, C., Maxson, D. A., Weickhardt, A. J., Oton, A. B., et al. (2012). Oncogene status predicts patterns of metastatic spread in treatment-naïve nonsmall cell lung cancer. Cancer, 118(18), 4502-4511.

15. Rangachari, D., Yamaguchi, N., VanderLaan, P. A., Folch, E., Mahadevan, A., Floyd, S. T., et al. (2015). Brain metastases in patients with EGFR-mutated or ALK-rearranged non-small-cell lung cancers. Lung Cancer, 88(1), 108-111.

16. Felip, E., Orlov, S., Park, K., Yu, CJ., Tsai, CM., Nishio, M., et al. (2015). ASCEND-3: a single-arm, open-label, multicenter phase II study of ceritinib in ALKi-naïve adult patients (pts) with ALKrearranged $(\mathrm{ALK}+)$ non-small cell lung cancer (NSCLC). J Clin Oncol, 33(supple; abstr 8060).

17. Shaw, A., Mehra, R., Tan, D., Felip, E., Chow, L. Q., Camidge, D. R., et al. (2014). Evaluation of ceritinib-treated patients with anaplastic lymphoma kinase rearranged $(\mathrm{ALK}+)$ non-small cell lung cancer (NSCLC) and brain metastases in the ASCEND-1 study. Annals of Oncology, 2(4), iv426-iv470. doi:10.1093/annonc/ mdu349.

18. Mok, T., Spigel, D., Felip, E., Ahn, MJ., Groen, MJA., Wakelee, HA., et al. (2015). ASCEND-2: a single-arm, open-label, multicenter phase II study of ceritinib in adult patients (pts) with ALKrearranged $(\mathrm{ALK}+$ ) non-small cell lung cancer (NSCLC) previously treated with chemotherapy and crizotinib (CRZ). J Clin Oncol, 33(supple; abstr 8059).

19. Ou, SH., Ahn, JS., Petris, LD., Govindan, R., Yang, JCH., Hughes, BGM., et al. (2015). Efficacy and safety of the ALK inhibitor alectinib in ALK+ non-small-cell lung cancer (NSCLC) patients who have failed prior crizotinib: an open-label, single-arm, global phase 2 study (NP28673). J Clin Oncol, 33(supple; abstr 8008).

20. Gandhi, L., Shaw, A., Gadgeel, SM., Riely, G., Cetnar, J., West, HJ., et al. (2015). A phase II, open-label, multicenter study of the ALK inhibitor alectinib in an ALK+ non-small-cell lung cancer (NSCLC) U.S./Canadian population who had progressed on crizotinib (NP28761). J Clin Oncol, 33(supple; abstr 8019).

21. Camidge, DR., Bazhenova, L., Salgia, R., Langer, CJ., Gold, KA., Rosell, R., et al. (2015). Safety and efficacy of brigatinib (AP26113) in advanced malignancies, including ALK+ non-small cell lung cancer (NSCLC). J Clin Oncol, 33(supple; abstr 8062).

22. Costa, D. B., Shaw, A. T., Ou, S. H., Solomon, B. J., Riely, G. J., Ahn, M. J., et al. (2015). Clinical experience with crizotinib in patients with advanced ALK-rearranged non-small-cell lung cancer and brain metastases. Journal of Clinical Oncology, 33(17), 18811888.

23. Ajimizu, H., Kim, Y. H., \& Mishima, M. (2015). Rapid response of brain metastases to alectinib in a patient with non-small-cell lung cancer resistant to crizotinib. Medical Oncology, 32(2), 477.

24. Ou, S. H., Sommers, K. R., Azada, M. C., Garon, E. B., et al. (2015). Alectinib induces a durable ( $>15$ months) complete response in an ALK-positive non-small cell lung cancer patient who progressed on crizotinib with diffuse leptomeningeal carcinomatosis. The Oncologist, 20(2), 224-226.

25. Gainor, J. F., Sherman, C. A., Willoughby, K., Logan, J., Kennedy, E., Brastianos, P. K., et al. (2015). Alectinib salvages CNS relapses 
in ALK-positive lung cancer patients previously treated with crizotinib and ceritinib. Journal of Thoracic Oncology, 10(2), 232-236.

26. Kodama, T., Hasegawa, M., Takanashi, K., Sakurai, Y., Kondoh, O., \& Sakamoto, H. (2014). Antitumor activity of the selective ALK inhibitor alectinib in models of intracranial metastases. Cancer Chemotherapy and Pharmacology, 74(5), 1023-1028.

27. Nanjo, S., Nakagawa, T., Takeuchi, S., Kita, K., Fukuda, K., Nakada, M., et al. (2015). In vivo imaging models of bone and brain metastases and pleural carcinomatosis with a novel human EML4ALK lung cancer cell line. Antitumor activity of the selective ALK inhibitor alectinib in models of intracranial metastases. Cancer Science, 106(3), 244-252.

28. Shaw, AT., Bauer, TM., Felip, E., Besse, B., James, LP., Clancy, JS., et al. (2015). Clinical activity and safety of PF-06463922 from a dose escalation study in patients with advanced ALK+ or ROS1+ NSCLC. J Clin Oncol, 33(supple; abstr 8018).

29. Sperduto, P. W., Kased, N., Roberge, D., Xu, Z., Shanley, R., Luo, X., et al. (2012). Summary report on the graded prognostic assessment: an accurate and facile diagnosis-specific tool to estimate survival for patients with brain metastases. Journal of Clinical Oncology, 30(4), 419-25.

30. Iwahara, T., Fujimoto, J., Wen, D., Cupples, R., Bucay, N., Arakawa, T., et al. (1997). Molecular characterization of ALK, a receptor tyrosine kinase expressed specifically in the nervous system. Oncogene, 14(4), 439-449.

31. Weickhardt, A. J., Scheier, B., Burke, J. M., Gan, G., Lu, X., Bunn, P. A., Jr., et al. (2012). Local ablative therapy of oligoprogressive disease prolongs disease control by tyrosine kinase inhibitors in oncogene-addicted non-small-cell lung cancer. Journal of Thoracic Oncology, 7(12), 1807-1814.

32. Nieder, C., Grosu, A. L., Astner, S., Thamm, R., \& Molls, M. (2006). Integration of chemotherapy into current treatment strategies for brain metastases from solid tumors. Radiation Oncology, 1, 19.

33. Sekine, A., Satoh, H., Iwasawa, T., Tamura, K., Hayashihara, K., Saito, T., et al. (2014). Prognostic factors for brain metastases from non-small cell lung cancer with EGFR mutation: influence of stable extracranial disease and erlotinib therapy. Medical Oncology. doi: 10.1007/s12032-014-0228-9.

34. Togashi, Y., Masago, K., Masuda, S., Mizuno, T., Fukudo, M., Ikemi, Y., et al. (2012). Cerebrospinal fluid concentration of gefitinib and erlotinib in patients with non-small cell lung cancer. Cancer Chemotherapy Pharmacology, 70(2012), 399-405.

35. Omuro, A. M., Kris, M. G., Miller, V. A., Franceschi, E., Shah, N., Milton, D., et al. (2005). High incidence of disease recurrence in the brain and leptomeninges in patients with nonsmall cell lung carcinoma after response to gefitinib. Cancer, 103(11), 2344-2348.

36. Iuchi, T., Shingyouji, M., Sakaida, T., Hatano, K., Nagano, O., Itakura, M., et al. (2013). Phase II trial of gefitinib alone without radiation therapy for Japanese patients with brain metastases from EGFR-mutant lung adenocarcinoma. Lung Cancer, 82(2), 282287.

37. Heon, S., Yeap, B. Y., Lindeman, N. I., Joshi, V. A., Butaney, M., Britt, G. J., et al. (2012). The impact of initial gefitinib or erlotinib versus chemotherapy on central nervous system progression in advanced non-small cell lung cancer. Clinical Cancer Research, 18(16), 4406-4414

38. Park, K., Ahn, M., Yu, C., Kim, S., Lin, M., Sriuranpong, V., et al. (2014). ASPIRATION: first-line erlotinib (E) until and beyond RECIST progression (PD) in Asian patients (pts) with EGFR mutation-positive (mut+) NSCLC. Annals of Oncology, 25(4), iv426-iv470. doi:10.1093/annonc/mdu349.

39. Kaneda, H., Okamoto, I., \& Nakagawa, K. (2013). Rapid response of brain metastases to crizotinib in a patients with ALK rearrangement-positive non-small-cell lung cancer. Journal of Thoracic Oncology, 8(4), e32-33.
40. Kinoshita, Y., Koga, Y., Sakamoto, A., \& Hidaka, K. (2013). Longlasting response to crizotinib in brain metastases due to EML4ALK-rearranged non-small-cell lung cancer. BMJ Case Report. doi:10.1136/bcr-2013-200867.

41. Peled, N., Zach, L., Liran, O., Ilouze, M., Bunn, P. A., Jr., \& Hirsch, F. R. (2013). Effective crizotinib schedule for brain metastases in ALK rearrangement metastatic non-small-cell lung cancer. Journal of Thoracic Oncology, 8(12), e112-e113.

42. Kim, Y. H., Ozasa, H., Nagai, H., Sakamori, Y., Yoshida, H., Yagi, Y., et al. (2013). High-dose crizotinib for brain metastases refractory to standard-dose crizotinib. Journal of Thoracic Oncology, 8(9), e85-86.

43. Costa, D. B., Kobayashi, S., Pandya, S. S., Yeo, W. L., Shen, Z., Tan, W., et al. (2011). CSF concentration of the anaplastic lymphoma kinase inhibitor crizotinib. Journal of Clinical Oncology, 29(15), e443-e445.

44. Chun, S. G., Choe, K. S., Iyengar, P., Yordy, J. S., \& Timmerman, R. D. (2012). Isolated central nervous system progression on crizotinib: an Achilles heel of non-small cell lung cancer with EML4ALK translocation? Cancer Biology and Therapy, 13(14), 13761383.

45. Gainor, J. F., Ou, S. H., Logan, J., Borges, L. F., \& Shaw, A. T. (2013). The central nervous system as a sanctuary site in ALKpositive non-small-cell lung cancer. Journal of Thoracic Oncology, 8(12), 1570-1573.

46. Metro, G., Lunardi, G., Floridi, P., Pascali, J. P., Marcomigni, L., Chiari, R., et al. (2015). CSF concentration of crizotinib in two ALK-positive non-small-cell lung cancer patients with CNS metastases deriving clinical benefit from treatment. Journal of Thoracic Oncology, 10(5), e26-27.

47. Sakamoto, H., Tsukaguchi, T., Hiroshima, S., Kodama, T., Kobayashi, T., Fukami, T. A., et al. (2011). CH5424802, a selective ALK inhibitor capable of blocking the resistant gatekeeper mutant. Cancer Cell, 19(5), 679-690.

48. Kodama, T., Tsukaguchi, T., Satoh, Y., Yoshida, M., Watanabe, Y., Kondoh, O., et al. (2014). Alectinib shows potent antitumor activity against RET-rearranged non-small cell lung cancer. Molecular Cancer Therapeutics, 13(12), 2910-2918.

49. Kodama, T., Tsukaguchi, T., Yoshida, M., Kondoh, O., \& Sakamoto, H. (2014). Selective ALK inhibitor alectinib with potent antitumor activity in models of crizotinib resistance. Cancer Letters, 351(2), 215-221.

50. Bartels, A. L., Kortekaas, R., Bart, J., Willemsen, A. T., de Klerk, O. L., de Vries, J. J., et al. (2009). Blood-brain barrier Pglycoprotein function decreases in specific brain regions with aging: a possible role in progressive neurodegeneration. Neurobiology of Aging, 30(11), 1818-1824.

51. Ohe, Y., Nishio, M., Kiura, K., Seto, T., Nakagawa, K., Maemondo, M., et al. (2015). A phase I/II study with a CNS-penetrant, selective ALK inhibitor alectinib in $A L K$-rearranged non-small cell lung cancer (ALK+ NSCLC) patients (pts): updates on progression free survival (PFS) and safety results from AF001JP. J Clin Oncol, 33(supple; abstr 8061).

52. Ou, S. H., Klempner, S. J., Azada, M. C., Rausei-Mills, V., \& Duma, C. (2015). Radiation necrosis presenting as pseudoprogression (PsP) during alectinib treatment of previously radiated brain metastases in ALK-positive NSCLC: implications for disease assessment and management. Lung Cancer, 88(3), 355-359.

53. Seto, T., Hida, T., Nakagawa, K., Satouchi, M., Nishio, M., Hotta, K., et al. (2014). Anti-tumor activity of alectinib in crizotinib pretreated ALK-rearranged NSCLC in JP28927 study. Annals of Oncology, 25(4), iv426-iv470. doi:10.1093/annonc/mdu349.

54. Friboulet, L., Li, N., Katayama, R., Lee, C. C., Gainor, J. F., Crystal, A. S., et al. (2014). The ALK inhibitor ceritinib overcomes 
crizotinib resistance in non-small cell lung cancer. Cancer Discovery, 4(6), 662-673.

55. Gainor, J. F., Tan, D. S., De Pas, T., Solomon, B. J., Ahmad, A., Lazzari, C., et al. (2015). Progression-free and overall survival in ALK-positive NSCLC patients treated with sequential crizotinib and ceritinib. Clinical Cancer Research, 21(12), 2745-2752.

56. Zykadia, C. (2014). US prescribing information. East Hanover, NJ: Novartis Pharmaceuticals Corporation.

57. Zou, H. Y., Friboulet, L., Kodack, D. P., Engstrom, L. D., Li, Q., West, M., et al. (2015). PF-06463922, an ALK/ROS1 inhibitor, overcomes resistance to first and second generation ALK inhibitors in preclinical models. Cancer Cell, 28(1), 70-81.

58. Horn, L., Infante, JR., Blumenschein, GR., Wakelee, HA., Arkenau, HT., Dukar, G., et al. (2014). A phase I trial of X-396, a novel inhibitor, in patients with advanced solid tumors. J Clin Oncol, 32:5s (supple; abstr 8030^).

59. Arkenau, HT., Sachdev, JC., Mita, MM., Dziadziuszko, R., Lin, CC., Yang, JCH., et al. (2015). Phase (Ph) 1/2a study of TSR-
011, a potent inhibitor of ALK and TRK, in advanced solid tumors including crizotinib-resistant ALK positive non-small cell lung cancer. J Clin Oncol, 33(supple; abstr 8063).

60. Gandara, D. R., Li, T., Lara, P. N., Kelly, K., Riess, J. W., Redman, M. W., et al. (2014). Acquired resistance to targeted therapies against oncogene-driven non-small-cell lung cancer: approach to subtyping progressive disease and clinical implications. Clinical Lung Cancer, 15(1), 1-6.

61. Takeda, M., Okamoto, I., \& Nakagawa, K. (2013). Clinical impact of continued crizotinib administration after isolated central nervous system progression in patients with lung cancer positive for ALK rearrangement. Journal of Thoracic Oncology, 8(5), 654-657.

62. Ou, S. H., Jänne, P. A., Bartlett, C. H., Tang, Y., Kim, D. W., Otterson, G. A., et al. (2014). Clinical benefit of continuing ALK inhibition with crizotinib beyond initial disease progression in patients with advanced ALK-positive NSCLC. Annals of Oncology, 25(2), 415-422. 